\section{Chlamydia pneumoniae infection-associated erythema multiforme}

\author{
Shinsaku Imashuku, Naoko Kudo \\ Division of Pediatrics and Hematology, \\ Takasago-seibu Hospital, Takasago, \\ Japan
}

\section{Abstract}

There is a well-known correlation between Herpes simplex (HSV) infection and erythema multiforme (EM). More recently, in Japan, it was found that Chlamydia pneumoniae (Cp) may promote the development of EM. All cases of Cp infection-associated EM that had been diagnosed in our clinic over the past two years (from 2011 to 2012) were analyzed. Cp infection was diagnosed on the basis of a significant increase $(>2.00)$ in anti-Cp IgM titers, as measured by the HITAZYME-ELISA test. There were 7 cases of Cp-EM, one male and 6 females. Median age was 13 years (range 3-29 years). It is recommended that the possible involvement of $\mathrm{Cp}$ infection, besides HSV or Mycoplasma pneumoniae infections, should be considered in all cases of EM.

\section{Introduction}

Erythema multiforme (EM) is a common skin rash that is thought to be mediated by the deposition of IgM-type immune complexes in the superficial microvasculature of the skin. There are two types of EM: EM minor, which is a mild, self-limited rash, and EM major, which is a severe, life-threatening rash that also involves mucous membranes. EM occurs mostly in the second and third decades of life but is also occasionally seen in childhood. Infection and exposure to drugs are suspected to be the causes of EM. While identifying the exact cause of EM is not an easy task, there is a well-known association between EM and Herpes simplex virus (HSV), particularly in the recurrent type of EM. ${ }^{1-4}$ With regard to other infectious causes, cases of Mycoplasma pneumoniae (Mp) infection-associated EM have been described in the literature.5,6 However, to date, little is known about the possible involvement of Chamydia pneumoniae (Cp) infection. ${ }^{7,8}$ In the present report, 7 cases of EM minor are described. All of these cases were eventually diagnosed as Cp infection-associated EM (Tables 1 and 2). To diagnose Cp infection, the patients with an EM skin rash underwent a HITAZYME-ELISA test that detects IgM antibodies against Cp. A Cp infection was diagnosed when the anti-Cp IgM titers exceeded 2.00, regardless of the anti-Cp IgA or IgG titers. ${ }^{9}$

\section{Case Report}

Seven patients (one male and 6 females; median age 13 years, range $3-29$ years) were diagnosed with EM in our clinic over the two years from 2011 to 2012 (Tables 1 and 2). In terms of underlying diseases, only one case (Case 2) had clearly identifiable collagen disease, namely systemic lupus erythematosus (SLE). Two others (Cases 3 and 7) also had high anti-nuclear antibody titers. Overall, the rashes developed on the face, trunk, buttock, upper arms, thighs, and other sites. Four of the 7 cases had symmetrical skin rashes on the upper arms (Figure 1 and Table 1). In 2 cases, treatment was intravenous drips of Stronger Neo-Minophagen C (glycyrrhetic acid/L-cysteine/glycine; Eisai); these 2 patients also received Clindamycin or valaciclovir (25 $\mathrm{mg} / \mathrm{kg} / \mathrm{d}$ ). A third case was treated with Celestamine. Four cases were not given specific treatment. The EM rashes disappeared within 5-7 days either spontaneously or in response to treatment. Cases 1 and 2 will be discussed in more detail below. Case 1 had had recurrent EMs before the index episode, namely at the ages of 1.6 years, 2.3 years and 5.7 years; the Cp infection was identified on the fourth episode at the age of six years. The EM episodes of this patient were all clinically similar. Unfortunately, the anti-Cp and anti-HSV titers in this patient had not been tested previously, and thus it is unclear whether HSV or Cp played a role in the previous episodes of EM. However, at least on the fourth episode, the patient did not have any herpetic lesions and was diagnosed with Cp-related EM because of positive anti-Cp IgM and negative anti-HSV IgM titers. With regard to Case 2, this patient was being treated for SLE with cyclosporine A and prednisolone when EM developed. This may explain why the anti-Cp IgM titers of this patient were slightly lower than 2.00 . While the EM would normally have to be differentiated from SLE-related skin lesions, the Cp-linked EM could be diagnosed this time because the patient did not have flare-up signs of SLE. With regards to Cases 3-7, it was the first time they had developed EM, and none had any remarkable underlying disease. Concerning other possible etiological infections, 3 of the 6 patients who were tested for anti-Mp antibody titers were positive. Thus, it is possible that, in those cases, the patients may have been infected with both $\mathrm{Cp}$ and $\mathrm{Mp}$. In addition, Case 3 had slightly increased anti-rubella IgM titers and Case 7 had elevated anticytomegalovirus (CMV) IgM titers. Thus, the
Correspondence: Shinsaku Imashuku, Consultant for Pediatrics and Hematology, Takasago-seibu Hospital, 1-10-41 Nakasuji, Takasago, 676-0812 Japan.

Tel. +81.79 .4470100 , Fax: +81.79 .4470180$

E-mail: shinim95@mbox.kyoto-inet.or.jp

Key words: erythema multiforme, Chlamydia pneumonia.

Contributions: SI and NK both took care of the patients; SI wrote the paper; both authors read and approved the final version of the manuscript for submission.

Conflict of interests: the authors declare no potential conflict of interests.

Received for publication: 12 November 2012. Accepted for publication: 17 April 2013.

This work is licensed under a Creative Commons Attribution NonCommercial 3.0 License (CC BYNC 3.0).

(C) Copyright S. Imashuku and N. Kudo, 2013 Licensee PAGEPress, Italy

Pediatric Reports 2013; 5:e9

doi:10.4081/pr.2013.e9

latter cases may have had $\mathrm{Cp}$ and viral coinfections.

\section{Discussion and Conclusions}

An analysis of this case series indicated the usefulness of examining anti-Cp IgM titers in all cases of EM, as this showed the true extent of $\mathrm{Cp}$ involvement in its development. Indeed, without this test, the association between EM and $\mathrm{Cp}$ infection would not have been suspected in these cases because they did not exhibit apparent respiratory infectious symptoms at the onset of disease. In fact, it was the unexpected experience in Case 1 that triggered our routine inclusion of the anti-Cp IgM test in all further cases of EM; this uncovered 6 more cases of Cp infection-associated EM in the following two years. In this case series, 3 of the 6 cases that were tested for Mp may have had a double infection with $\mathrm{Cp}$ and Mp. This is consistent with a previous report that described Cp/Mp double infection-associated EM. ${ }^{8}$ While it has been suggested that Mp infection-related EM tends to be the EM major type, with bullous-type eruptions, mucositis, and StevensJohnson syndrome (SJS), 5,6 the eruptions in the present cases were all of the EM minor type, namely neither the exudative nor the SJS type, as shown in Figure 1. Although the fact 
Table 1. Clinical features of 7 cases of Chlamydia pneumoniae (Cp)-related erythema multiforme.

\begin{tabular}{|c|c|c|c|c|c|c|c|}
\hline & Case 1 & Case 2 & Case 3 & Case 4 & Case 5 & Case 6 & Case 7 \\
\hline Age (years)/gender & $6 / \mathrm{M}$ & $19 / \mathrm{F}$ & $15 / \mathrm{F}$ & $13 / \mathrm{F}$ & $4 / F$ & $3 / \mathrm{F}$ & $29 / \mathrm{F}$ \\
\hline \multicolumn{8}{|l|}{ Signs/lab data } \\
\hline URTI & no & yes & no & yes & no & yes & yes \\
\hline Adenopathy & no & yes & no & no & no & no & no \\
\hline LRTI & yes & no & no & no & no & no & no \\
\hline Sites of rash & $\begin{array}{l}\text { face, trunk, } \\
\text { buttock }\end{array}$ & $\begin{array}{l}\text { neck, trunk, } \\
\text { upper arms, hands }\end{array}$ & $\begin{array}{l}\text { thighs, } \\
\text { upper arms }\end{array}$ & $\begin{array}{l}\text { face, upper arms, } \\
\text { abdomen, thighs }\end{array}$ & $\begin{array}{l}\text { face, upper } \\
\text { arms, buttock }\end{array}$ & face, trunk & hands, feet \\
\hline \multicolumn{8}{|l|}{ Treatment/outcome } \\
\hline Duration of rash $\mathrm{Rx}$ & $\begin{array}{c}<5 \text { days } \\
\mathrm{mPSL} / \mathrm{SNMCNACV}\end{array}$ & $\begin{array}{c}7 \text { days } \\
\text { SNMC/CLDM } \\
(\mathrm{CSA} / \mathrm{PSL})^{*}\end{array}$ & $\begin{array}{l}7 \text { days } \\
\text { no ST }\end{array}$ & $\begin{array}{c}<5 \text { days } \\
\text { no ST }\end{array}$ & $\begin{array}{c}5 \text { days } \\
\text { Celestamine }\end{array}$ & $\begin{array}{l}<5 \text { days } \\
\text { No ST }\end{array}$ & $\begin{array}{l}7 \text { days } \\
\text { No ST }\end{array}$ \\
\hline
\end{tabular}

mPSL, methylprednisolone; SNMC, stronger neo-minophagen C; VACV, valaciclovir; CLDM, clindamycin; Celestamine, d-chlorphnylamine-malenate/betamethasone; ST, specific treatment; URTI, upper respiratory tract infection; LRTI, lower respiratory tract infection. *This case was being treated with CSA (cyclosporine A) and PSL (prednisolone) for underlying systemic lupus erythematosus.

Table 2. Laboratory data of 7 cases of Chlamydia pneumoniae (Cp)-related erythema multiforme.

\begin{tabular}{|c|c|c|c|c|c|c|c|}
\hline & Case 1 & Case 2 & Case 3 & Case 4 & Case 5 & Case 6 & Case 7 \\
\hline $\mathrm{WBC}(\times 109 / \mathrm{L})$ & 15.4 & 4.3 & 3.1 & 4.2 & 7.0 & 3.3 & 6.5 \\
\hline $\mathrm{Hb}(\mathrm{g} / \mathrm{dL})$ & 14.0 & 11.8 & 14.0 & 13.7 & 12.0 & 13.3 & 12.5 \\
\hline PLTs $(\times 109 / \mathrm{L})$ & 291 & 172 & 173 & 127 & 420 & 141 & 224 \\
\hline CRP (mg/dL) & 0.02 & 0.04 & 0.95 & 0.12 & 0.05 & 0.03 & 0.08 \\
\hline ANA & NT & 640 & 80 & NT & NT & NT & 40 \\
\hline Mp-Ab (PA) & 40 & $<40$ & 40 & 80 & $<40$ & $<40$ & NT \\
\hline Cp-IgA EIA & $0.996(-)$ & $0.095(-)$ & $1.469(+/-)$ & $1.486(+/-)$ & $2.606(+)$ & $0.057(-)$ & $1.305(+/-)$ \\
\hline Cp-IgG EIA & $2.046(+)$ & $0.275(-)$ & $2.939(+)$ & $1.249(+/-)$ & $2.335(+)$ & $0.047(-)$ & $2.130(+)$ \\
\hline Cp-IgM EIA & $5.638(+)$ & $1.964(+/-)$ & $2.018(+)$ & $3.947(+)$ & $7.331(+)$ & $2.416(+)$ & $5.934(+)$ \\
\hline Rubella-IgG & NT & $6.4(+)$ & $<0.8$ & $<2.0$ & $53.3(+)$ & NT & NT \\
\hline Rubella-IgM & NT & $<0.8$ & $0.98(+/-)$ & $<0.8$ & $<0.8$ & NT & NT \\
\hline HSV-IgG & $<2.0(-)$ & NT & NT & NT & NT & NT & NT \\
\hline HSV-IgM & $<0.8(-)$ & NT & NT & NT & NT & NT & NT \\
\hline CMV-IgG & NT & NT & NT & NT & NT & NT & $24.7(+)$ \\
\hline CMV-IgM & NT & NT & NT & NT & NT & NT & $9.01(+)$ \\
\hline
\end{tabular}

WBC, white blood cells; Hb, Hemoglobin; PLTS, platelets; CRP, C-reactive protein; ANA, antinuclear antibody; Mp, Mycoplasma pneumoniae; Cp, Chlamydia pneumoniae; Ig, Immunoglobulin; NT, not tested; HSV, herpes simplex virus; CMV, cytomegalovirus.

that erythema nodosum can be a manifestation of Cp infection was first described in 1989,10 the characteristic clinical features and the mechanisms by which Cp-related skin eruptions develop remain poorly understood. To diagnose $\mathrm{Cp}$ infection effectively, we employed the HITAZYME-ELISA method with the generally accepted cut-off value for ELISA Cp IgM titers of over 2.00.9

In summary, it would have been difficult to suspect $\mathrm{Cp}$ infection in the present cases of EM if testing for anti-Cp-IgM antibodies had not been performed because 6 of the 7 cases did not have any apparent lower respiratory tract infectious signs, although 4 of these 7 cases did have upper respiratory infectious symptoms with fever. Thus, it is recommended that all cases of EM should be tested for Cp infection and not only for HSV or Mp infections.

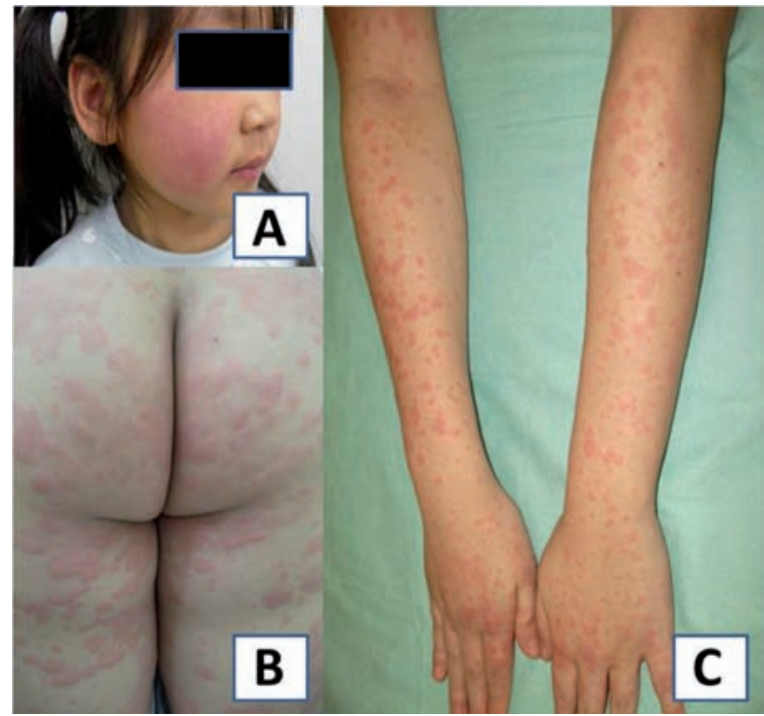

Figure 1. Various forms of geographically distributed non-exudative erythematous eruptions. A) Case 5, B) Case 1 and C) Case 2. 


\section{References}

1. Goldberg LH, Sperber J. Erythema multiforme due to herpes simplex: treatment with oral acyclovir. South Med J 1986; 79:757-9.

2. Huff JC. Acyclovir for recurrent erythema multiforme caused by herpes simplex. J Am Acad Dermatol 1988;18:197-9.

3. Schofield JK, Tatnall FM, Leigh IM. Recurrent erythema multiforme: clinical features and treatment in a large series of patients. Br J Dermatol 1993;128:542-5.

4. Weston WL, Morelli JG. Herpes simplex virus-associated erythema multiforme in prepubertal children. Arch Pediatr Adolesc 1997;151:1014-6.

5. Schalock PC, Dinulos JG, Pace N, et al. Erythema multiforme due to Mycoplasma pneumoniae infection in two children. Pediatr Dermatol 2006;23:546-55.

6. Atkinson TP, Boppana S, Theos A, et al. Stevens-Johnson syndrome in a boy with macrolide-resistant Mycoplasma pneumoniae pneumonia. Pediatrics 2011;127: e1605-9.

7. Hosokawa R, Kobayashi T, Higashino T, et al. Two cases of erythema exsudativum multiforme associated with Chlamydia pneumoniae infection. J Dermatol 2012; 39:306-8.
8. Terada K, Hiraga Y, Mori R, et al. [Double infection of Chlamydia pneumoniae and Mycoplasma pneumoniae in children]. Kansenshogaku Zasshi 1996;70:1176-80. [Article in Japanese].

9. Kamata A, Obinata K, Niizuma T, et al. The validity of the criteria for primary infection of Chlamydophila pneumoniae in children by measuring ELISA IgM antibodies. J Infect Chemother 2012;18:308-12.

10. Erntell M, Ljunggren K, Gadd T, Persson K. Erythema nodosum-a manifestation of Chlamydia pneumoniae (strain TWAR) infection. Scand J Infect Dis 1989;21:693-6. 